\title{
IbM PENGEMBANGAN RAJUTAN DI KAMPUNG AUR MEDAN
}

\author{
Budi Agustono $^{1)}$, Mhd. Pujiono ${ }^{2)}$, Niza Ayuningtias ${ }^{3)}$ \\ Fakultas Ilmu Budaya Universitas Sumatera Utara \\ ${ }^{1)}$ email : agustono_budi@yahoo.com \\ ${ }^{2)}$ email : mhd.puhjiono@usu.ac.id \\ ${ }^{3)}$ email : niza.ayuningtias@yahoo.com
}

\begin{abstract}
ABSTRAK
Pengabdian masyarakat berupa pengembangan rajutan di kampung Aur Medan merupakan suatu kegiatan yang efektif dalam meningkatkan produktifitas masyarakat dalam menghasilkan barang rajutan yang berkualitas. Dalam pengabdian ini tim Pengabdian kepada Masyarakat FakultasIlmuBudayaUniversitas Sumatera Utara akan mengadakan workshop dan pendampingan dalam merajut. Metode yang digunakan dalam kegiatan workshop adalah metode ceramah, tanya jawab, demonstrasi dan simulasi. Metode ceramah dan tanya Jawab digunakan untuk memberikan pengetahuan dan teori-teori mengenai teknik dan cara merajut. Metode Simulasi dan demonstrasi digunakan agar masyarakat dapat mempraktekkan materi yang telah diterima sebelumnya. Setelah workshop dilaksanakan, tim pengabdian kepada masyarakat juga akan membantu membangun sanggar rajut sebagai tempat unuk memberikan pendampingan kepada masyarakat secara berkala.
\end{abstract}

Kata Kunci: Pengembangan rajutan, Workshop, Kampung Aur Medan

\author{
IbM DEVELOPMENT OF KNITWEAR IN KAMPUNG AUR MEDAN \\ Budi Agustono $^{1)}$, Mhd. Pujiono ${ }^{2)}$, Niza Ayuningtias ${ }^{3)}$ \\ Faculty of Cultural Science, University of Sumatera Utara \\ ${ }^{1)}$ email : agustono_budi@yahoo.com \\ ${ }^{2)}$ email : mhd.puhjiono@usu.ac.id \\ 3) email : niza.ayuningtias@yahoo.com
}

\begin{abstract}
Community service in the form of knit development in KampungAur Medan is an effective activity in improving the productivity of society in producing quality knitwear. In this program, devotion team of the Faculty of Cultural Sciences University of Sumatera Utara will hold workshops and mentoring in knitting. The methods used in the workshop are lecture, question and answer, demonstration and simulation. Lecture and $Q \& A$ methods are used to provide knowledge and theories about techniques and knitting. Simulation and demonstration methods are used so that people can practice materials that have been previously accepted. After the workshop is held, the team of community service will also help build a knitting house as a place to provide assistance to the community on a regular basis.
\end{abstract}

Keywords: Development of knitwear, Workshop, Kampung Aur Medan

\section{PENDAHULUAN}

Pemberdayaan masyarakat sangat penting untuk dilakukan mengingat pertumbuhan ekonomi dan teknologi yang semakin pesat di era globalisasi dewasa saat ini. Hal-hal yang berkaitan dengan hal pertuumbuhan dan perkembangan ekonomi dan teknologi di masyarakat akan mempengaruhi kemampuan tiap individu dalam memenuhi kebutuhan hidupnya. Oleh 
karena itu, pemberdayaan masyarakat di berbagai bidang murupakan hal yang sangat dibutuhkan, khususnya dalam bidang ekonomi.

Upaya pemberdayaan ekonomi masyarakat tidak terlepas dari perluasan kesempatan kerja dan peningkatan pendapatan masyarakat. Terkait dengan pemberdayaan masyarakat dalam memperluas kesempatan kerja, salah satunya dipengaruhi oleh kebijakan pengembangan Usaha Mikro, Kecil dan Menengah (UMKM). Pengembangan UMKM terutama Usaha Kecil Menengah (UKM), memiliki potensi yang strategis dalam rangka pemberdayaan masyarakat, sehingga mampu memberikan nilai tambah bagi masyarakat, yaitu tersedianya lapangan kerja dan meningkatnya pendapatan. Hal ini menunjukkan bahwa kelompok UKM dapat menjadi penyeimbang, pemerataan dan penyerap tenaga kerja. Pemberdayaan dalam hal ini dilakukan dengan peningkatan akses bantuan modal usaha, peningkatan akses ke sarana dan prasarana yang mendukung masyarakat lokal serta peningkatan akses pengembangan kualitas Sumber Daya Manusia (SDM).

Kota Medan merupakan penyumbang terbesar penyandang masalah kesejahteraan sosial yang berkaitan dengan Perempuan Rawan Sosial Ekonomi (PRSE). Menurut data dari Kantor Wilayah Departemen Sosial Provinsi Sumatera Utara, terdapat 412,575 Perempuan Rawan Sosial Ekonomi di Kota
Medan. Mereka adalah bagian dari masalah kesejahteraan sosial di Kota Medan.

Kampung Aur merupakan salah satu kawasan yang terletak di Kelurahan Air, Kecamatan Medan Maimun, Kota Medan. Menurut data dari kelurahan Aur, kelurahan Aur termasuk dalam salah satu daerah pemukiman padat penduduk di Kota Medan dengan populasi 9.086 jiwa dalam 2469 rumah tangga. Kepadatan penduduk ini tentunya akan mendatangkan banyak masalah, khususnya dalam hal sarana dan prasarana tempat bermukim masyarakat serta masalah dibidang ekonomi. Namun disisi lain banyaknya populasi di kawasan ini dapat menjadi potensi pengembangan sumber daya manusia dalam rangka pemberdayaan ekonomi masyarakat di kawasan tersebut.

Sebagian besar wanita di kawasan Kampung Auradalah ibu rumah tangga. Karena itu, pengembangan industri rumahan kreatif merupakan salah satu cara yang tepat dalam rangka peningkatan peluang pemberdayaan ekonomi di kawasan tersebut. Salah satu industri rumahan kreatif tersebut yaitu dalam bidang barang rajutan.

Telah terdapat komunitas yang bergerak di bidang Industri kreatif rajutan di Kampung Aur Medan, salah satunya komunitas yang disebut dengan Gerakan Mamak-mamak Rajut (GEMAR). GEMAR merupakan komunitas yang dibentuk oleh Yayasan Fajar Sejahtera Indonesia (YAFSI), sebuah yayasan yang secara khusus 
melakukan banyak kegiatan pemberdayaan masyarakat baik di bidang pendidikan maupun kesehatan di Indonesia. Namun dalam perjalananya GEMAR banyak menghadapi kendalam dan kekurangan dalam kegiatannya.

Dalam upaya merealisasikan secara optimal pemberdayaan masyarakat Kampung Aur melalui pengembangan industri rumahan kreatif barang rajutan, maka hal yang diperlukan yaitu bantuan modal usaha untuk kelengkapan sarana dan prasarana yang mendukung serta pengembangan kualitas Sumber Daya Manusia (SDM) berupa keterampilan dalam bidang merajut.

Untuk itu perlu dilaksanakan suatu kegiatan yang berorientasi pada pengembangan dan peningkatan kualitas masyarakat khususnya ibu-ibu rumah tangga di Kampung Aur dalam hal merajut. Kegiatan tersebut yaitu berupa workshop merajut dan pendampingan dalam menjalankan industri rumahan kreatif rajutan di kawasan Kampung Aur Medan.

Dengan penjelasan di atas maka dapat dirumuskan permasalahan dalam makalah ini sebagai berikut :

1. Bagaimana upaya pengembangan kualitas rajutan bagi masyarakat Kampung Aur Medan?

2. Bagaimana upaya menfasilitasi dan pendampingan dalam aktifitas pengembangan industri rumahan kreatif barang rajutan bagi masyarakat Kampung Aur Medan?

\section{METODE PELAKSANAAN}

Dalam upaya memberdayakan masyarakat Kampung Aur dalam pengembangan rajutan, maka tim pengabdian kepada masyarakat akan melaksanakan kegiatan workshop dan pendampingan pada masyarakat di Kampung Aur.

Kata workshop berasal dari bahasa Inggris yang berarti lokakarya, mengandung pengertian suatu acara untuk beberapa orang berkumpul untuk memecahkan masalah tertentu dan mencari solusinya. Ditinjau dari tempat pelaksanaannya metode pelatihan dapat dikelompokan menjadi dua sebagai berikut (Waluyo, 2014:16).

a) On the job training atau pelatihan di tempat kerja. Metodenya seperti demonstrasi, praktik langsung, metode mengerjakan sendiri, dan rotasi kerja.

b) Off the job training atau pelatihan di luar tempat kerja. Metodedalam pelatihan ini, seperti role play atau permainan peran dandiskusi.

Workshop merajut dan pendampingan yang dilakukan akan melibatkan 40 orang wanita yang berprofesi sebagai ibu rumah tangga dan berdomisili di Kampung Aur. Penentuan peserta workshopdengan cara interview pra-workshop yang dilakukan atas kerjasama dengan mitra pengabdian Yayasan Fajar Sejahtera Indonesia (YAFSI) dan 
Gerakan Mamak-Mamak Merajut (GEMAR) yang telah lebih dahulu banyak melakukan kegiatan pemberdayaan bersama masyarakat di Kampung Aur.Metode yang digunakan dalam kegiatan workshop ini adalah metode ceramah, metode tanya jawab, simulasi dan demonstrasi.

\section{Metode Ceramah}

Metode ceramah digunakan untuk memberikan penjelasan tentang pengetahuan dasar tentang barang rajutan beserta teknik dan cara merajut kepada para peserta workshop. Motode ini juga menekankan pada upaya memotivasi para peserta agar memiliki kemauan serta meningkatkan pemahaman mengenai pembuatan barang-barang rajutan.

\section{Metode Diskusi dan Tanya Jawab}

Metode diskusi dan tanya jawab dilakukan karena sangat penting bagi para peserta Workshop untuk mengetahui kemampuannya dalam menerima penjelasan tentang pengetahuancara dan teknik merajut. Metode ini memungkinkan para peserta untuk menggali sebanyak mungkin pengetahuan mengenai pembuatan barangbarang rajutan.

\section{Metode Simulasi}

Menurut definisi Depdiknas (2005:133) "Metode pembelajaran simulasi adalah bentuk metode praktek yang sifatnya untuk mengembangkan keterampilan peserta didik (ranah kognitif maupun keterampilan).” Metode ini memindahkan suatu situasi yang nyata ke dalam kegiatan atau ruang belajar karena adanya kesulitan atau keterbatasan untuk melakukan praktek di dalam situasi yang sesungguhnya.

Sedangkan, menurut Bahri (2006:90) Metode pembelajaran simulasi adalah cara penyajian pelajaran dengan meragakan atau mempertunjukan kepadasiswa suatu proses, situasi atau benda tertentu yang sedang dipelajari, baik sebenarnya ataupun tiruan yang sering disertai dengan penjelasan lisan.

Metode simulasi dianggap sangat penting diberikan kepada para peserta simulasi agar mereka mampu mempraktekkan materi teoridalam workshop yang telah diterima. Melalui simulasi diharapkan para peserta whorkshop mampu juga mengidentifikasikan segala bentuk kesulitan yang mungkin muncul serta mampu memecahkannya.

Untuk mencapai pelaksanaan metode yang diuraikan pada metode penelitian, maka perlu dibuat langkah-langkah model pembelajaran dalam simulasi sebagai berikut :

\section{Model Demonstrasi}

Menurut Nana Sudjana (2010: 121), model demonstrasi adalah suatu metode mengajar memperhatikan bagaimana jalannya suatu proses terjadinya sesuatu. Bahri (2006: 210), menjelaskan bahwa "model demonstrasi adalah pertunjukan tentang terjadinya suatu peristiwa atau benda sampai pada penampilan tingkah laku yang dicontohkan agar dapat diketahui dan 
dipahami oleh peserta didik secara nyata atau tiruannya".

Sementara itu, menurut Wianat (2004: 424), "model demonstrasi adalah cara penyajian materi pelajaran dengan mempertunjukkan secara langsung objek atau cara melakukan sesuatu untuk mempertunjukkan proses tertentu".

\section{Merajut (Knitting)}

Merajut (Knitting) berarti menyatukan benang menjadi kain memakai dua jarum. Knitting memerlukan minimal empat jarum untuk membuat rajutan memutar, merajut dengan teknik knitting menghasilkan rajutan yang lebih ringan dan melar (Sitoresmi, 2011 :9).

Alat yang umumnya digunakan adalah jarum rajut. Jarum rajut untuk knitting biasa disebut dengan knitting needle. Jarum knit ini populer juga dengan sebutan breien. Breien memiliki ujung yang runcing, tapi tidak seruncing jarum untuk menjahit. Jarum breien ukurannya sangat bervariatif, mulai 1,25 mm hingga $20 \mathrm{~mm}$. Bahan jarum knit ini yang umum adalah besi, aluminium, bambu dan plastik, dipegang oleh tangan kanan dan kiri.

Tipe jarum knit ini terbagi menjadi tiga, yaitu; single pointed (satu ujung runcing), double pointed (dua ujung runcing) dan circular (melingkar). Pada jarum knit single pointed, satu ujungnya runcing, sedangkan ujung lainnya berbentuk bulat besar (atau bentuk lainnya) yang lebih besar daripada diameter jarum untuk mencegah benang selip/tergelincir.

Teknik dasar dalam knitting adalah knit dan purl. Knit adalah dari arah belakang. Knit menghasilkan tampilan seperti rantai vertikal, sementara purl menghasilkan tampilan seperti jelujur horizontal. Dua teknik dasar ini bisa dikembangkan menjadi bermacam-macam pola yang menghasilkan berbagai karya rajutan yang bagus.

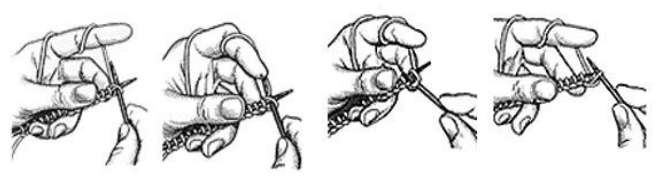

Gambar 1. Teknik Knit

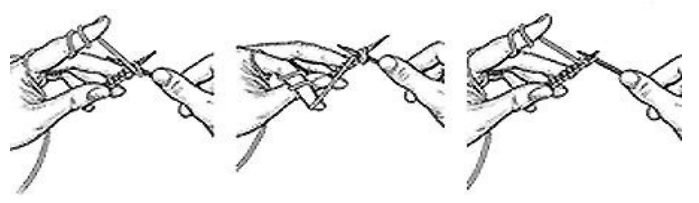

Gambar 2. Teknik purl

\section{PEMBAHASAN}

Mengadakan Workshop Sebagai Upaya pengembangan kualitas rajutan bagi masyarakat Kampung Aur Medan

Pentingnya pengembangan rajutan di

Kampung Aur Medan merupakan salah satu cara meningkatkan produktivitas masyarakat serta menambah pendapatan ekonomi masyarakat. Oleh karena itu, perlu dilaksanakan workshop merajut bagi masyarakat di Kampung Aur Medan.

Pembekalan dan pengembangan kemampuan merajut masyarakat Kampung Aur Medan di dalam workshop sebaiknya menggunakan beberapa metode supaya 
menghasilkan simulasi yang lebih terarah dan efektif bagi peserta workshop.

Dalam workshop ini tim pengabdian masyarakat akan mengundang para praktisi dan pakar di bidang merajut. Akan digunakan gambar-gambar sebagai media simulasi dan pembekalan. Gambar-gambar tersebut tentunya yang mempunyai hubungan dengan pengetahuan $d$ ibidang bahan dan teknik merajut. Hal ini bertujuan supaya peserta workshop dapat memahami, mengerti dan mempraktekkan cara merajut dengan baik dan benar. Selain itu untuk melihat hasil maksimal yang dicapai, maka peserta workshop diwajibkan mempraktekkan dan menghasilkan satu karya rajutan secara langsung. Selain itu akan diberikan pendampingan pasca workshop selama beberapa minggu untuk memastikan rencana tindak lanjut dari workshop terus terealisasi sesuai dengan yang diharapkan.

Kegiatan Pengabdian dan pendampingan ini memiliki manfaat mengembangkan kualitas rajutan bagi masyarakat Kampung Aur Medan dan memfasilitasi dan memberikan pendampingan dalam aktifitas pengembangan industri rumahan kreatif barang rajutan bagi masyarakat Kampung Aur Medan.

Pada tahap awal untuk pelaksanaan ini yaitu melakukan koordinasi ke kantor kepala kepala lingkungan kampung Aur, Medan mengenai izin untuk melaksanakan kegiatan di wilayah tersebut dan juga berkoordinasi dengan mitra pengabdian tentang sarana prasarana serta bahan-bahan yang digunakan untuk kegiatan workshop dan pendampingan pembuatan dan koleksi desain-desain yang dihasilkan. Kegiatan pembuatan koleksi desain dan mengumpulkan desain-desain yang ada mulai dilakukan pada tanggal 26 Mei sampai dengan bulan Juni 2017 yang juga disi dengan memberikan bantuan bahan baku benang dan alat kepada mitra untuk diberikan kepada pengerajin pada saat kegiatan workshop. Kegiatan pelatihan dan pembuatan koleksi desain dilaksanakan bersama antara tim pengusul dengan para mitra dan pengerajin rajutan yang didasarkan pada permasalahan yang dihadapi oleh kelompok pengerajin rajutan. Kegiatan ini dilaksanakan beberapa pertemuan di kantor Program Studi sastra Cina Fakultas Ilmu Budaya USU.

Tahap selanjutnya adalah mempersiapkan instruktur yang menguasai bidang-bidang yang akan dilatihkan kepada para peserta. Persiapan instruktur ini meliputi: pembuatan materi pelatihan, baik dalam bentuk bahan cetak mapun media lain, mempersiapkan materi pelatihan untuk pelatihan dan pendampingan pembuatan modul sederhana, pelatihan dan pendampingan mengenai teknik dasar merajut dan variasi-variasi motif, desain rajutan yang ada sesuai kebutuhan yang ada di pasar. Pada tahap selanjutnya adalah 
melakukan musyawarah untuk perencanaan pembangunan sanggar rajut bagi Ibu-ibu pengrajut di Kampung Aur Medan. Hal ini dilaksanakan akan nantinya sanggar yang dibangun tidak mendapat kendala sosial di lingkungan masyarakat kampung Aur Medan. Koordinasi juga dilakukan kepada kepala desa dan kepala lingkungan untuk mendapatkan izin kegiatan dan mendapatkan legitimasi dari pemerintahan desa, sehingga kegiatan pembangunan dapat berlangsung dengan lancar.

\section{Pelaksanaan Workshop}

Workshop merajut dilaksanakan pada tanggal 19 Agustus 2017 bertempat di Balai Kampung Aur, Medan. Kegiatan workshop ini melibatkan 40 orang Ibu-ibu rumah tangga yang berdomisili di Kampung Aur. Peserta workshopadalaha peserta hasil interview pra-workshop yang telah dipilih oleh mitra tim pengabdian yaitu Yayasan Fajar Sejahtera Indonesia (YAFSI) dan Gerakan Mamak-Mamak Merajut (GEMAR).

Kegiatan dimulai pada pukul 10.00 WIB, dimulai dengan acara pembukaan yang berisi sambutan dari Mitra pengabdian Ibu Badriyah, S.Sos., selaku ketua YAFSI, ketua tim pengabdian Dr. Budi Agustono, dan perwakilan Kepala Desa.Setelah sambutan diteruskan pada kegiatan worshop hingga pukul 12.00 WIB. Setelahnya istirahat hingga pukul 14.00 WIB yang diisi dengan solat dan makan siang bersama peserta workshop.
Kemudian acara workshop dilanjutkan hingga pukul 16.00 WIB.

Metode yang digunakan dalam kegiatan workshop ini adalah metode ceramah, metode tanya jawab, simulasi dan demonstrasi. workshop merajut ini dimulai dari pemberikan materi tentang alat-alat dan bahan yang digunakan untuk merajut. Diteruskan denga bentuk rajutan, jenis dan bentuk motif rajutan, dan pengembangan motif rajutan sesuai dengan kebutuhan pasar.

Peserta mengikuti dengan antusias terhilat dari keaktifan para peserta untuk bertanya kepada narasumber hal-hal yang berkaitan dengan rajutan. seperti alat-alat, teknik rajutan dan sebagainya.

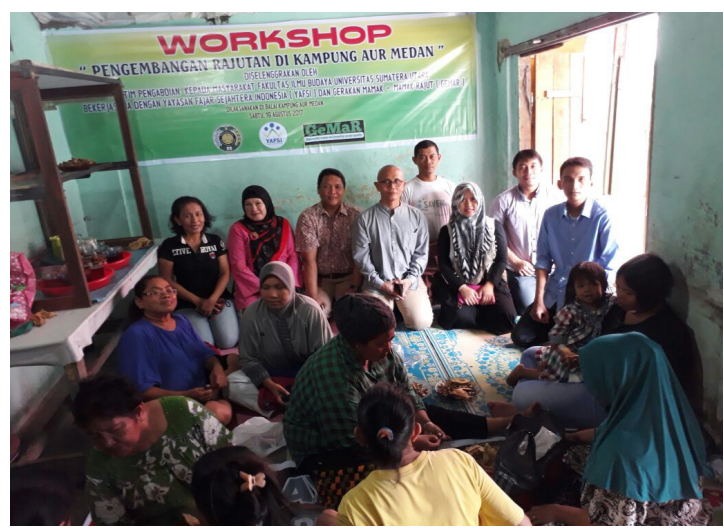

Gambar 3. Foto Tim Pengabdian berdama Mitra

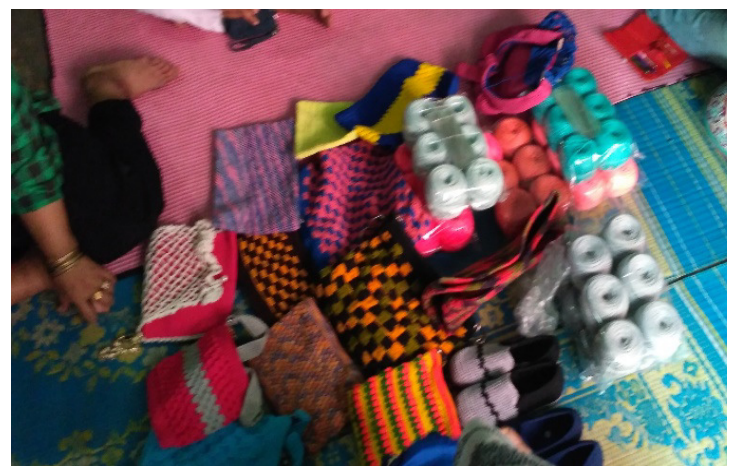

Gambar 4. Bahan dan hasil rajutan 


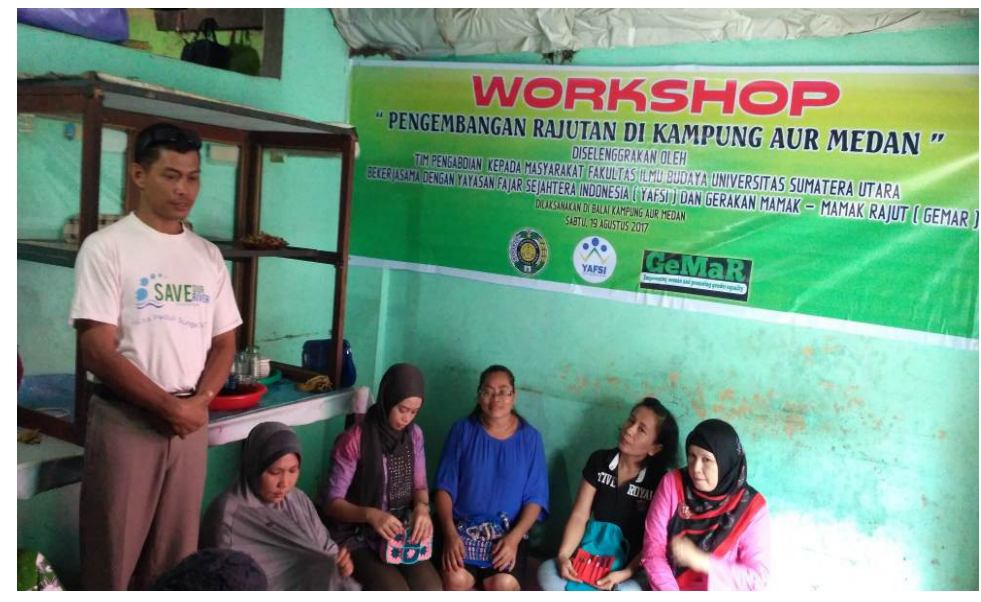

Gambar 5. Sambutan Kepala Desa
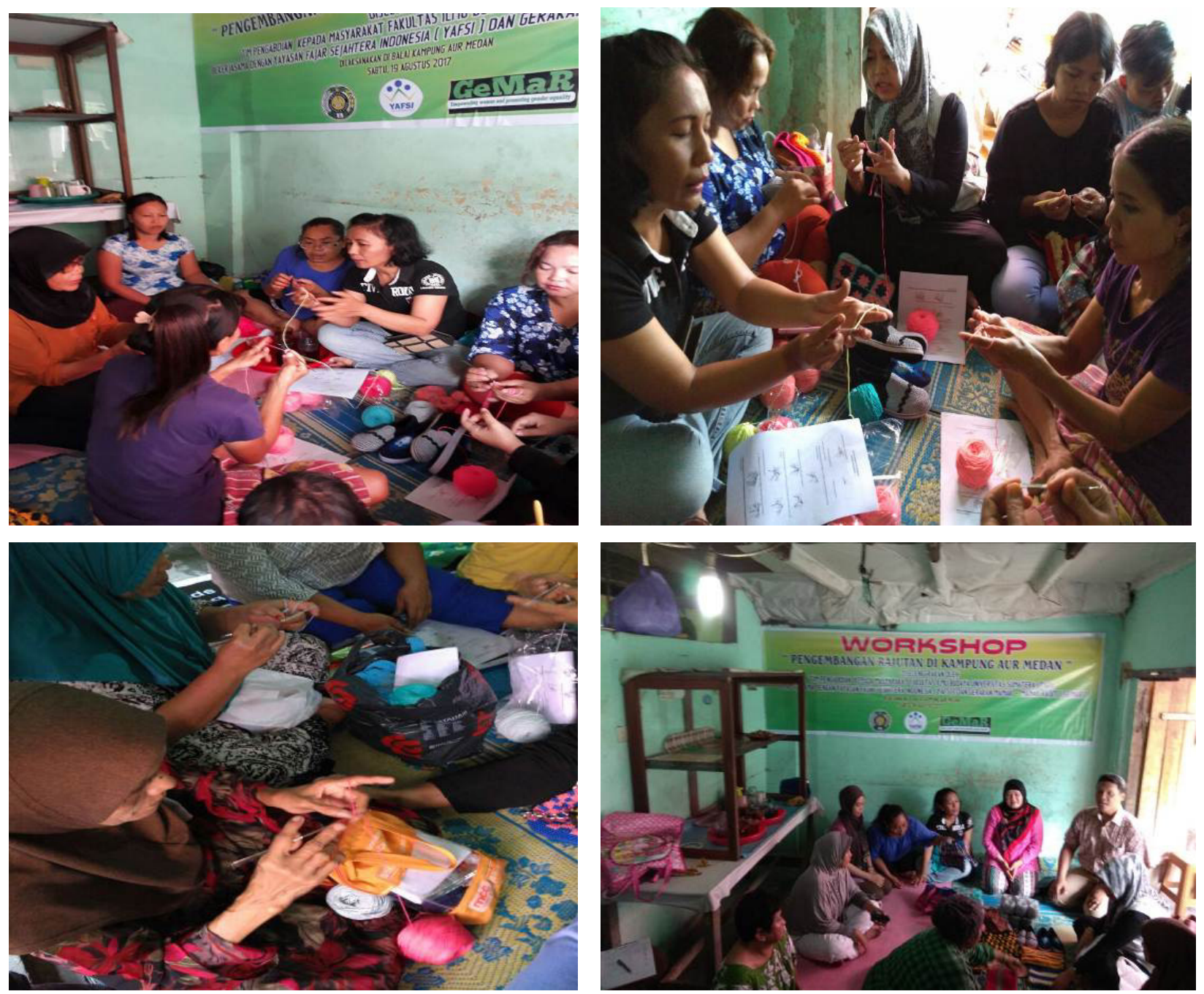

Gambar. 6. Pelaksanaan Workshop 


\section{Pembangunan Sanggar Rajut Sebagai Upaya Menfasilitasi dan Pendampingan dalam Aktifitas Pengembangan Industri Rumahan Kreatif Barang Rajutan bagi Masyarakat Kampung Aur Medan}

Sebagai upaya menfasilitasi antusias ibu-ibu pengrajut di kampung Aur Medan khususnya para peserta workshop merajut, tim pengabdian masyarakat juga akan membantu membangun sanggar rajut di kampung Aur Medan. Sanggar rajut akan dibangun di salah satu lahan kosong milik salah satu warga kampung Aur yang juga merupakan salah satu pengrajut aktif di kampung Aur Medan.

Sanggar rajut yang dibangun direncanakan berukuran $5 \quad$ X 7 Meter, berlokasi di pinggir Sungai Deli. Sanggar rajut ini nantinya diharapkan akan digunakan untuk aktivitas komunitas rajut di kapung Aur Medan dalam meningkatkan kemampuan merajut dan pengembangan potensi merajut ibu-ibu pengrajut. Saat ini pembangunan sudah dalam proses pembersihan lahan dan pengerjaan.

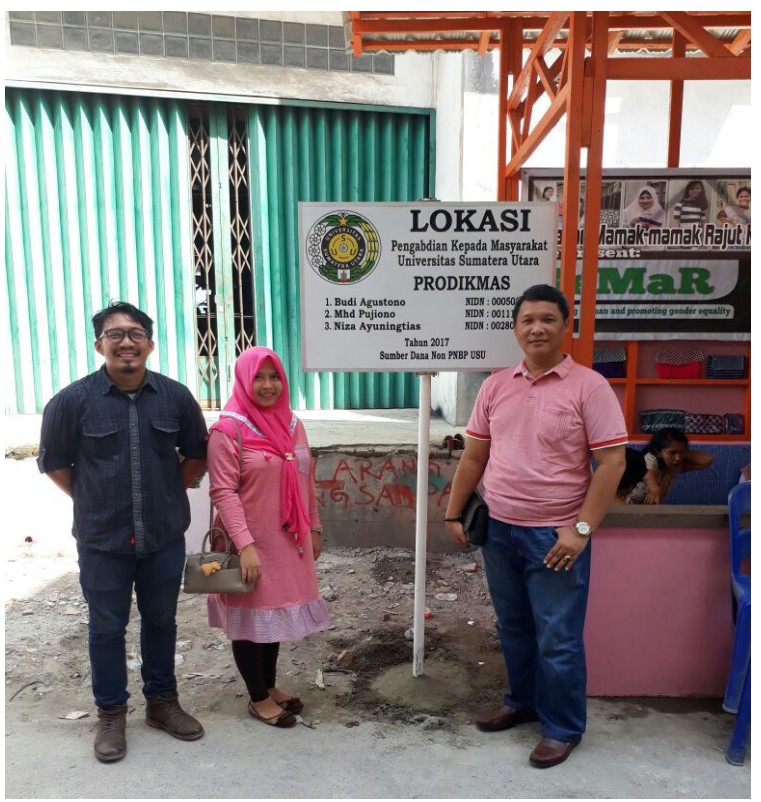

Gambar 7. Lokasi Pembangunan Sanggar Rajut

\section{KESIMPULAN DAN SARAN}

\section{Kesimpulan}

Dalam upaya merealisasikan secara optimal pemberdayaan masyarakat Kampung Aur melalui pengembangan industri rumahan kreatif barang rajutan, maka tim Pengabdian Kepada Masyarakat Fakultas Ilmu Budaya Universitas Sumatera Utara bersama dengan mitra pengabdian yaitu, Yayasan Fajar Sejahtera Indonesia (YAFSI) dan Gerakan Mamak-Mamak Merajut (GEMAR) melakukan upaya pengembangan kualitas rajutan bagi masyarakat Kampung Aur Medan. Upaya tersebut yaitu melaksanakan kegiatan workshop merajut dan pendampingan dalam menjalankan industri rumahan kreatif rajutan di kawasan Kampung Aur Medan. 
Kemudian dalam upaya menfasilitasi dan pendampingan dalam aktifitas pengembangan industri rumahan kreatif barang rajutan bagi masyarakat Kampung Aur Medan,Timpengabdian kepada Masyarakat juga memberikan bantuan berupa pembangunan sanggar rajut bagi komunitas merajut di Kampung Aur. Tim Pengabdian Kepada Masyarakat memantau secara langsung proses pembangunan sehingga proses penyaluran bantuan bahan dan pengerjaan sanggar rajut dapat sesuai dengan harapan Tim pengabdian, mitra maupun para pengrajut di Kampung Aur Medan.

\section{Saran}

Diperlukan usaha-usaha tertentu dalam upaya peningkatan produktifitas masyarakat khususnya masyarakat menengah kebawah. Salah satu cara peningkatan produktivitas masyarakat dapat dilakukan dengan pemberdayaan masyarakat diberbagai kalangan dan bidang.

Kalangan Ibu Rumah Tangga adalah salah satu yang memiliki potensi besar untuk diberdayakan. Potensi tersebut dapat berupa pengembangan industri-insutri rumahan kreatif. Karena itu sebaiknya diperlukan kegiatan-kegiatan yang difokuskan untuk membantu pengembangan industri-insutri rumahan kreatif tersebut.

\section{REFERENSI}

Bahri, Syaiful. 2006. Strategi Belajar Mengajar. Jakarta: Rineka Cipta

Depdiknas. 2005. Kumpulan Metode Pembelajaran/ Pendampingan.[online]. http.

www.media.diknas.go.id/media/documen t/3553.pdf(10 Mei 2017)

Nana Sujdana. 2010. Penilaian Hasil Proses Belajar Mengajar. Bandung: Remaja Rosdakarya.

Poerwadarminta. 1996. Kamus Umum Bahasa Indonesia. Jakarta : PN Balai Pustaka

Sitoresmi, A. G. (2011). "Sehari Mahir Merajut". Penerbit Pustaka Grhatama. Yogyakarta.

Waluyo, Muji. 2014.In-On-In-On Plus TB Model Peningkatan Kompetensi Supervisi Akademik bagi Kepala Sekolah Binaan di Kabupaten Temanggung. UMYPress

Wianata, Putra, dkk. 2004.strategi Belajar

Mengajar. Jakarta: Universitas Terbuka 